\title{
DETERMINATION OF THE INFLUENCE OF THE PHASE COMPOSITION OF CU-Bi COATINGS ON THE EFFICIENCY OF SHIELDING FROM IONIZING RADIATION.
}

\author{
Kadyrzhanov K.K. ${ }^{1}$, Shlimas D.I. ${ }^{1}$, Kaniukov E.Yu. ${ }^{2}$, Kaliyekperov M.E. ${ }^{1}$ \\ 1'L.N. Gumilyov Eurasian National University, Nur-Sultan, Kazakhstan, kayrat.kadyrzhanov@mail.ru \\ ${ }^{2}$ Scientific-Practical Materials Research Centre of National Academy of Sciences of Belarus, Minsk, \\ Belarus
}

\begin{abstract}
The work is devoted to the study of the efficiency of shielding the radiation exposure of heavy ions depending on the phase composition of $\mathrm{Cu}$-Bi coatings. As a method of producing protective coatings, an electrochemical deposition method was used. The change in phase composition was carried out by varying the applied potentials difference during deposition. The study found that the change in phase composition leads to an increase in coating density, as a result of the dominance of the $\mathrm{CuBi}_{2} \mathrm{O}_{4}$ phase and an increase in the structural ordering degree. During shielding efficiency tests, it was found that the greatest decrease in the degree of crystallinity is observed for copper coatings, for which the amorphization of the structure at the maximum irradiation fluence didn't exceed $12 \%$, while for coatings based on $\mathrm{CuBi}_{2} \mathrm{O}_{4}$ the value of amorphization was no more than $1.2 \%$ of initial value. Amorphization and fragmentation of grains at high radiation doses leads to a decrease in the shielding efficiency, as well as an increase in the value of the deviation $\Delta U$.
\end{abstract}

Keywords: protective coatings, shielding, ionizing radiation, heavy ions, radiation resistance.

\section{Introduction}

The rapid development of technologies in the field of nuclear energy and reactor building is inextricably linked to the problem of radiation safety and protection against the negative impact of ionizing radiation [13]. In the transition to the widespread use of microelectronic devices, as well as the reduction in the size of semiconductor chips, their resistance to the destabilizing effects of ionizing radiation plays a large role. Reduction of mass-dimensional dimensions of microelectronic devices led to a sharp decrease in the level of natural protection against ionizing radiation $[4,5]$. At the same time, a negative impact that leads to destabilization of performance and failure can lead to both long-term irradiation and a single cascade of secondary dislodged particles caused by the collision of a heavy ion [6-10]. Radiation-resistant materials based on nitrides [11-13], carbides [14, 15] or nanostructured films and coatings are used as the most common methods of protection against ionizing radiation.

The most promising solution to the problem of maintaining the stability of microelectronic devices operating in conditions of high radiation background is the use of composite protective coatings of complex composition [16-20]. The choice of protective coatings is based on the principles of preservation of physical, chemical and mechanical properties as a result of prolonged exposure to external factors and loads [21-24]. Moreover, it should be noted that in most cases it is impossible to create a protective coating capable of protecting against all types of exposure, but at the same time it is possible to significantly reduce one or another type of radiation that can cause the greatest negative impact on performance [25-27].

The purpose of this work is to study the possibility of using $\mathrm{Cu}$-Bi films for protection against heavy ions, as well as the effect of the phase composition on the efficiency of shielding and weakening the negative impact on microelectronic circuits. Copper-bismuth $(\mathrm{Cu}-\mathrm{Bi})$ - based coatings were selected as research objects to determine the effect of the crystal structure, including the phase composition of the synthesized coatings, as well as surface morphology (grain size) on the shielding efficiency [28,29]. The choice of this type of coating is due to the possibility of obtaining coatings with different phase compositions, including both two-phase and single-phase coatings. The change in phase composition, and hence crystal structure, can have a significant impact on shielding efficiency by varying coating density as well as absorption capacity 
and affecting energy losses. The change in grain size has a great effect on dislocation density, which can also lead to strengthening of coatings and reduction of radiation damage.

\section{Experimental part}

As a method of obtaining protective coatings, the method of electrochemical deposition from electrolyte solutions was chosen: $\mathrm{CuSO}_{4} \cdot 5 \mathrm{H}_{2} \mathrm{O}(238 \mathrm{~g} / \mathrm{l}), \mathrm{Bi}_{2}\left(\mathrm{SO}_{4}\right)_{3}(10 \mathrm{~g} / \mathrm{l}), \mathrm{H}_{2} \mathrm{SO}_{4}(21 \mathrm{~g} / \mathrm{l})$ [28,29]. The applied potentials difference for deposition was varied from $1.5 \mathrm{~V}$ to $2.0 \mathrm{~V}$. The change in the applied potentials difference is due to the possibility of varying the phase composition of the synthesized coatings.

Evaluation of structural changes and phase composition of the synthesized samples was carried out using the method of X-ray phase analysis performed on a D8 Advance ECO X-ray diffractometer.

$\mathrm{Xe}^{22+}$ ions with an energy of $230 \mathrm{MeV}$ and fluences of $10^{13}-10^{15}$ ions $/ \mathrm{cm}^{2}$ were selected for shielding efficiency tests. The irradiation was performed on a DC-60 heavy ion accelerator [12]. The choice of fluences is due to the possibility of modeling the effects of overlapping defect areas that occur during irradiation. With the selected energy of incident ions, the path length in the selected materials for testing exceeds $12-20 \mu \mathrm{m}$, depending on the type of ions, comparable to the thickness of the films.

The efficiency of shielding radiation damage caused by ionizing radiation will be assessed according to the method of determining the preservation of the performance of microcircuits by measuring deviations in volt-ampere characteristics before and after irradiation. The threshold value $\Delta \mathrm{U}$, which is characteristic of critical malfunctions of the microcircuits, will be selected as $0.1 \mathrm{~V}$. Deviation of the volt-ampere characteristic above the threshold value leads to deterioration of the microcircuit and its further failure.

\section{Results and discussion}

Table 1 shows the initial data of the test coatings that were used to test the absorption efficiency. The thickness of the protective coatings was $10 \mu \mathrm{m}$. As can be seen from the data presented in Table 1, by changing the synthesis conditions, in particular the applied potential difference, it is possible to control the phase composition of the synthesized coatings to obtain both single-phase coatings consisting of copper or $\mathrm{CuBi}_{2} \mathrm{O}_{4}$ and a mixed composition. At the same time, the change in phase composition leads to an increase in the density of the coatings, as a result of the dominance of the $\mathrm{CuBi}_{2} \mathrm{O}_{4}$ phase and an increase in the degree of structural ordering (degree of crystallinity). However, in the case where the $\mathrm{CuBi}_{2} \mathrm{O}_{4}$ phases in the coating composition become larger, an increase in grain size is observed, and thereby a decrease in dislocation density.

Table 1 - Initial sample data.

\begin{tabular}{|c|c|c|c|c|c|}
\hline $\begin{array}{c}\text { Conditions for } \\
\text { obtaining }\end{array}$ & $\begin{array}{c}\text { Phase composition, } \\
\text { phase ratio }\end{array}$ & $\begin{array}{l}\text { Average crystallite } \\
\text { size, nm } \\
\end{array}$ & $\begin{array}{c}\text { Density, } \\
\mathrm{g} / \mathrm{cm}^{3}\end{array}$ & $\begin{array}{c}\text { Crystallinity } \\
\text { degree, } \%\end{array}$ & $\begin{array}{c}\text { Dislocation } \\
\text { density, } 10^{11} \mathrm{~cm}^{-2} \\
\end{array}$ \\
\hline $1.5 \mathrm{~V}$ & $\mathrm{Cu}-\mathrm{FCC}-100 \%$ & 73.5 & 9.17 & 81.2 & 0.185 \\
\hline $1.6 \mathrm{~V}$ & $\begin{array}{c}\mathrm{Cu}-\mathrm{FCC}-75 \% \\
\mathrm{CuBi}_{2} \mathrm{O}_{4}-\mathrm{HCP}- \\
25 \%\end{array}$ & 78.3 & 11.42 & 85.3 & 0.163 \\
\hline $1.75 \mathrm{~V}$ & $\begin{array}{c}\mathrm{Cu}-\mathrm{FCC}-25 \% \\
\mathrm{CuBi}_{2} \mathrm{O}_{4}-\mathrm{HCP}- \\
75 \%\end{array}$ & 84.5 & 12.44 & 88.3 & 0.141 \\
\hline $2.0 \mathrm{~V}$ & $\begin{array}{c}\mathrm{CuBi}_{2} \mathrm{O}_{4}-\mathrm{HCP}- \\
100 \%\end{array}$ & 96.3 & 12.48 & 89.7 & 0.108 \\
\hline
\end{tabular}

To assess the effect of phase composition and crystal structure on shielding efficiency, $\mathrm{Xe}^{22+}$ ions with an energy of $230 \mathrm{MeV}$ and fluences of $1 \times 10^{13}-10^{15} \mathrm{ion} / \mathrm{cm}^{2}$ were selected as ionizing radiation. Evaluation of efficiency of radiation damage shielding caused by ionizing radiation was carried out according to the method of determining serviceability of microcircuits by measuring deviations of volt-ampere characteristics before and after irradiation. The threshold value $\Delta \mathrm{U}$, which is characteristic of critical malfunctions of the microcircuits, was selected as $0.1 \mathrm{~V}$. Deviation of the volt-ampere characteristic above the threshold value leads to deterioration of the microcircuit and its further failure. Figure 1 shows experimental data of $\Delta \mathrm{U}$ value change depending on irradiation dose for all tested coating samples. 


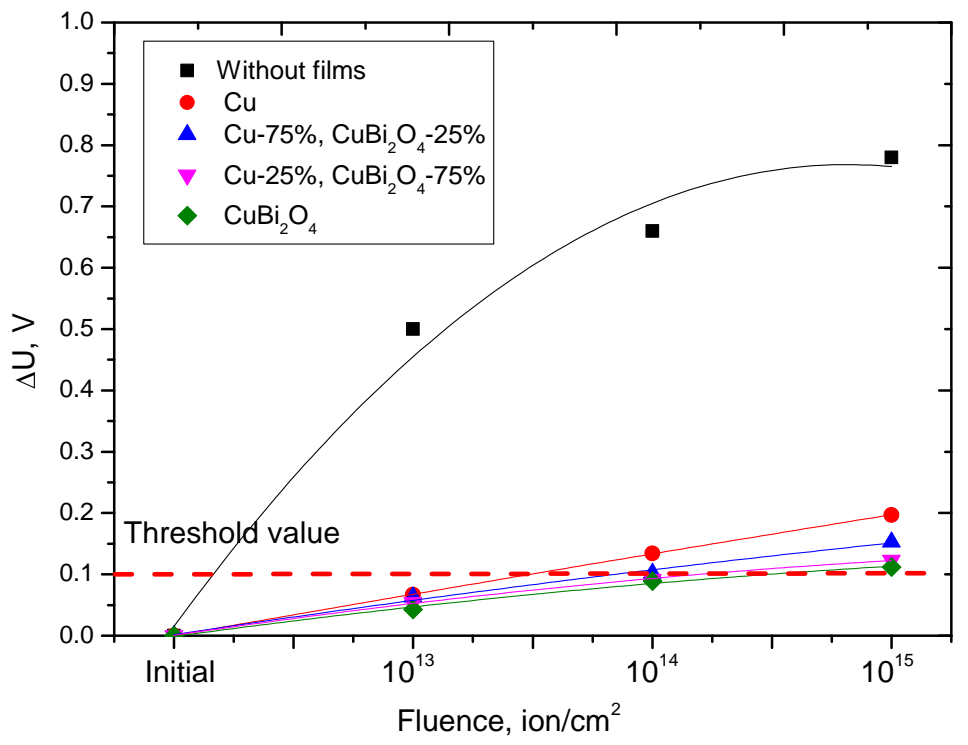

Fig.1. Data on changes in the value of $\Delta \mathrm{U}$ depending on the radiation dose

As can be seen from the presented data, at a radiation dose of $1013 \mathrm{ion} / \mathrm{cm}^{2}$, all the tested protective coatings show a high level of absorption of radiation damage, and the deviation $\Delta \mathrm{U}$ does not exceed 0.05 $0.06 \mathrm{~V}$. However, an increase in the radiation dose leads to a significant change in the behavior of $\Delta \mathrm{U}$ for the studied coatings. For coatings with a crystalline structure characteristic of copper, as well as with a large content of the $\mathrm{Cu}-\mathrm{FCC}$ phase in the structure, a decrease in absorption efficiency is observed, and an increase in $\Delta \mathrm{U}$ value that exceeds the threshold value. Further increase of irradiation dose results in deviation of $\Delta \mathrm{U}$ value being more than $0.15-0.17 \mathrm{~V}$, which indicates sharp decrease of absorption capacity of coatings and deterioration of protection degree.

For coatings dominated by the $\mathrm{CuBi}_{2} \mathrm{O}_{4}$ phase, as well as single-phase coatings based on $\mathrm{CuBi}_{2} \mathrm{O}_{4}$, the deviation of $\Delta \mathrm{U}$ is significantly lower than for copper coatings, indicating a higher degree of resistance to radiation damage and a high degree of absorption of radiation damage. Figure 2 shows a graph for evaluating the efficiency of reducing radiation damage at maximum irradiation fluence, which was calculated as a result of a comparative analysis with the deviation of the $\Delta \mathrm{U}$ value for microcircuits without protective coatings.

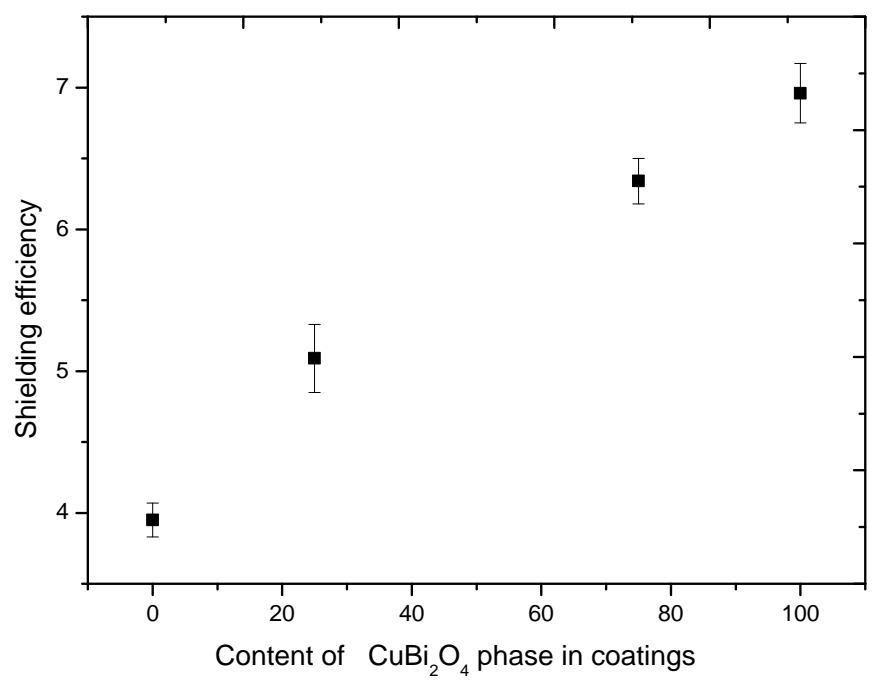

Fig.2. Graph of radiation damage reduction efficiency assessment at maximum radiation fluence.

As can be seen from the data presented, coatings based on $\mathrm{CuBi}_{2} \mathrm{O}_{4}$ for which the value of the shielding efficiency was 6.96 are most effective. The increase in shielding efficiency for coatings is $\mathrm{CuBi}_{2} \mathrm{O}_{4}$ associated with high radiation resistance to radiation damage, as well as resistance of the crystal structure to degradation and amorphization as a result of irradiation. Figure 3 shows the data of changes in the value of 
the degree of structural ordering as a result of irradiation, as well as an estimate of the change in grain sizes and dislocation density (see Figure 4).

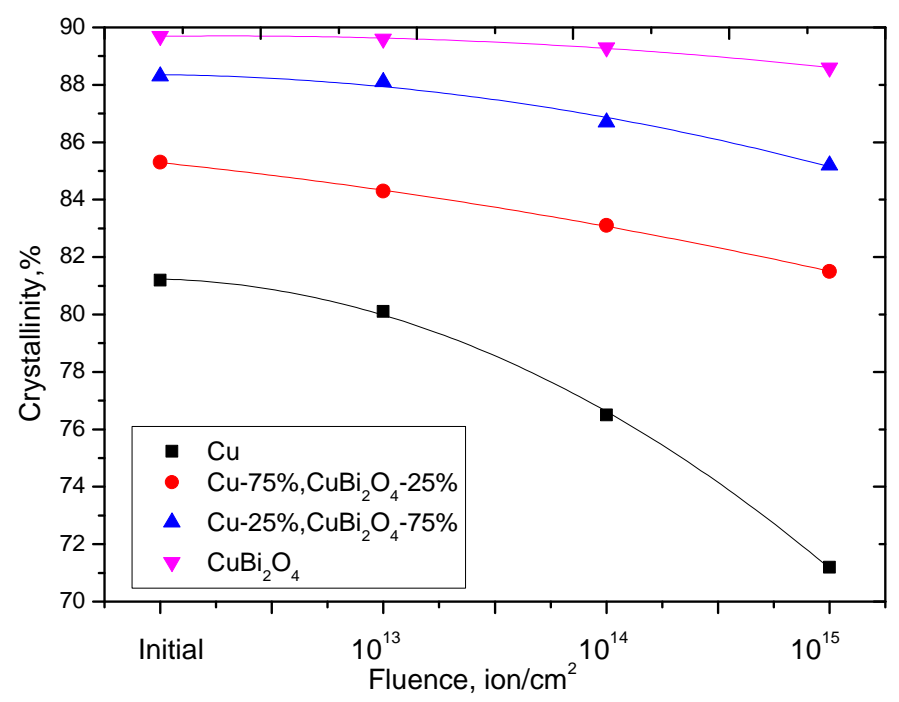

Fig.3. Dynamics of changes in the degree of crystallinity of the coatings under study depending on the radiation dose

As can be seen from the data presented, the greatest decrease in crystallinity is observed for copper coatings, for which amorphization of the structure at maximum irradiation fluence was more than $12 \%$, while for coatings based on $\mathrm{CuBi}_{2} \mathrm{O}_{4}$, the value of amorphization didn't exceed $1.2 \%$ of the initial value. A high degree of amorphization for copper coatings leads to disordering of the crystal structure, large deformations of the crystal lattice, crushing of crystallites and an increase in dislocation density. According to the presented dependences, the change in the grain size for coatings containing $\mathrm{CuBi} 2 \mathrm{O} 4$ with an increase in the radiation dose is less pronounced than for copper coatings. At the same time, an increase in the radiation dose leads to the processes of grain fragmentation, thereby increasing the dislocation density of defects.

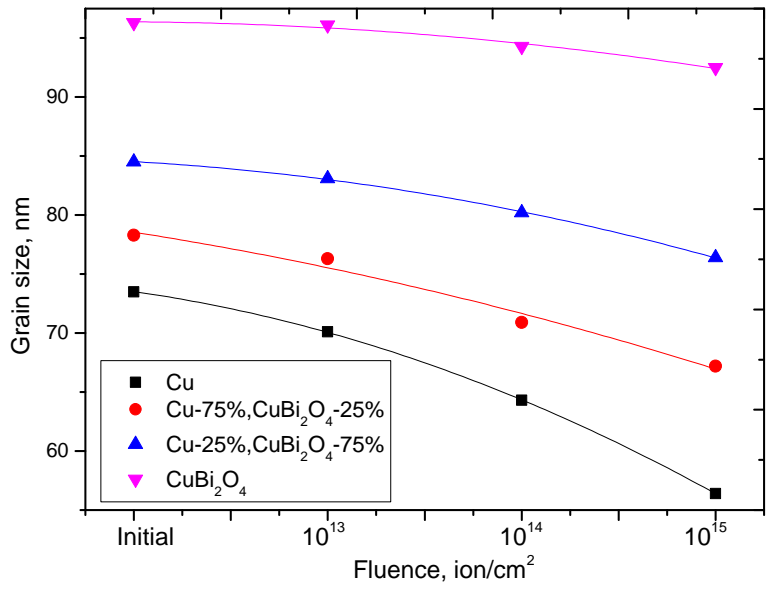

a

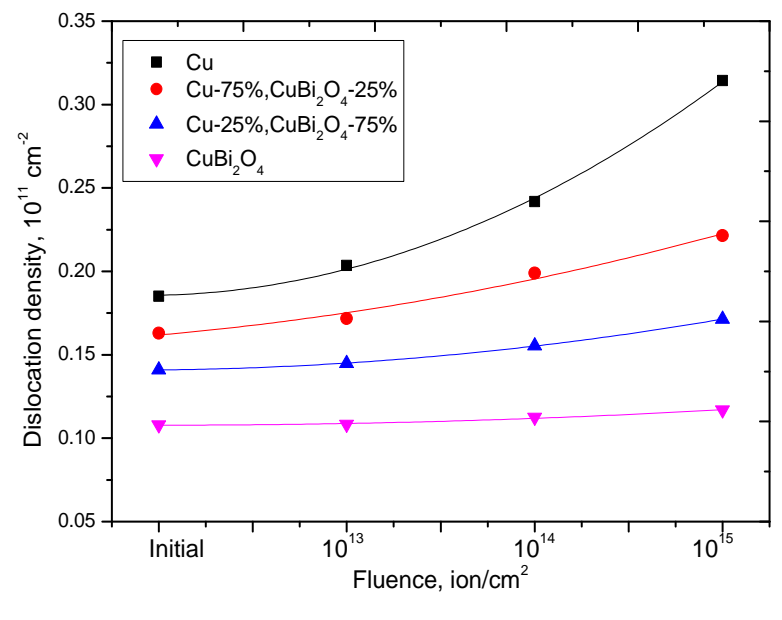

b

Fig.4. Graphs of changes in structural parameters: a) Change of grain size depending on radiation dose;

b) Change of dislocation density depending on radiation dose.

Thus, during the study, it was found that a change in the crystal structure, including the phase composition of synthesized coatings, leads to an increase in the efficiency of shielding ionizing radiation, as well as a decrease in the degree of amorphization of coatings as a result of the accumulation of radiation damage. The amorphization and crushing of grains at high radiation doses leads to a decrease in the shielding efficiency, as well as an increase in the deviation $\Delta \mathrm{U}$. It has been found that coatings based on $\mathrm{CuBi}_{2} \mathrm{O}_{4}$ have 
the best radiation resistance to degradation and amorphization, as well as the efficiency of shielding from ionizing radiation.

\section{Conclusion}

During the study, it was found that a change in the crystal structure, including the phase composition of the synthesized coatings. This change leads to an increase in the shielding efficiency of ionizing radiation, as well as a decrease in the degree of amorphization of coatings as a result of the accumulation of radiation damage. Amorphization and fragmentation of grains at high radiation doses leads to a decrease in the shielding efficiency, as well as an increase in the value of the deviation $\Delta \mathrm{U}$. It was found that the best radiation resistance to degradation and amorphization, as well as the efficiency of shielding from ionizing radiation, is possessed by $\mathrm{CuBi}_{2} \mathrm{O}_{4}$-based coatings. In the future, studies to compare the shielding efficiency of synthesized coatings with commercial analogues based on silicon carbide, titanium nitride, aluminum nitride and tungsten oxide will be carried out.

\section{REFERENCES}

1 Sayyed M. I. et al. Physical, structural, optical and gamma radiation shielding properties of borate glasses containing heavy metals (Bi2O3/MoO3). Journal of Non-Crystalline Solids, 2019, Vol.507, pp. 30 - 37.

2 Ryskulov A. E. et al. The effect of Ni12+ heavy ion irradiation on the optical and structural properties of $\mathrm{BeO}$ ceramics. Ceramics International, 2020, Vol. 46(4), pp. 4065 - 4070.

3 Kurudirek M. Heavy metal borate glasses: potential use for radiation shielding. Journal of Alloys and Compounds, 2017, Vol. 727, pp. $1227-1236$.

4 Kumar A. et al. Physical, structural, optical and gamma ray shielding behavior of (20+x) PbO-10 $\mathrm{BaO}-10$ Na2O-10 MgO-(50-x) B2O3 glasses. Physica B: Condensed Matter, 2019, Vol. 552, pp. 110 - 118.

5 Kozlovskiy A. et al. Structure and corrosion properties of thin $\mathrm{TiO} 2$ films obtained by magnetron sputtering. Vacuum, 2019, Vol. 164, pp. $224-232$.

6 Zdorovets M. V. and Kozlovskiy A. L. Argon ion irradiation effect on Zn nanotubes. Journal of Materials Science: Materials in Electronics, 2018, Vol. 29(5), pp. 3621 - 3630.

7 Raghuvanshi S. et al. Dual control on structure and magnetic properties of Mg ferrite: role of swift heavy ion irradiation. Journal of Magnetism and Magnetic Materials, 2019, Vol. 471, pp. 521 - 528.

8 Kozlovskiy A. et al. Investigation of the influence of irradiation with $\mathrm{Fe}+7$ ions on structural properties of AlN ceramics. Materials Research Express, 2018, Vol. 5(6), pp. 065502.

9 Mirzayev Matlab N. et al. Thermophysical behavior of boron nitride and boron trioxide ceramics compounds with high energy electron fluence and swift heavy ion irradiated. Journal of Alloys and Compounds, 2020, Vol. 834, pp.155119.

10 Rammah Y. S., et al. FTIR, electronic polarizability and shielding parameters of B2O3 glasses doped with SnO2. Applied Physics A, 2018, Vol. 124(9), p. 650.

11 Kozlovskiy A. et al. Optical and structural properties of AlN ceramics irradiated with heavy ions. Optical Materials, 2019, Vol. 91, pp. 130 - 137.

12 Kozlovskiy A. et al. Dynamics of changes in structural properties of AlN ceramics after Xe+ 22 ion irradiation. Vacuum, 2018, Vol. 155, pp. $412-422$.

13 Kozlovskiy A. L. et al. Radiation resistance of thin TiN films as a result of irradiation with low-energy Kr14+ ions. Ceramics International, 2020, Vol. 46(6), pp. 7970 - 7976.

14 Tunhuma S. M. et al. Defects in swift heavy ion irradiated n-4H-SiC. Nuclear Instruments and Methods in Physics Research Section B: Beam Interactions with Materials and Atoms, 2019, Vol. 460, pp. 119 - 124.

15 Zdorovets M.V., Kurlov A.S. and Kozlovskiy A. L. Radiation defects upon irradiation with Kr14+ ions of TaC0. 81 ceramics. Surface and Coatings Technology, 2020, Vol. 386, pp. 125499.

16 Tinishbaeva K. et al. Implantation of low-energy Ni 12+ ions to change structural and strength characteristics of ceramics based on SiC. Journal of Materials Science: Materials in Electronics, 2020. Vol. 31(3), pp. 2246 - 2256.

17 Zdorovets M. V., Kozlovskiy A. L. The effect of lithium doping on the ferroelectric properties of LST ceramics. Ceramics International, 2020, Vol. 46(10), pp. 14548 - 14557.

18 Tekin $\mathrm{H}$. O. et al. The investigation of gamma-ray and neutron shielding parameters of $\mathrm{Na}_{2} \mathrm{O}-\mathrm{CaO}-\mathrm{P} 2 \mathrm{O} 5-$ $\mathrm{SiO}_{2}$ bioactive glasses using MCNPX code. Results in Physics, 2019, Vol. 12, pp. 1797 - 1804.

19 Rammah Y. S. et al. Optical properties and gamma-shielding features of bismuth borate glasses. Applied Physics A, 2018, Vol. 124(12), pp. 832.

20 Chung Cheng-Kai et al. Thermodynamic and structural evolution of mechanically milled and swift heavy ion irradiated Er2Ti2O7 pyrochlore. Acta Materialia, 2019, Vol. 181, pp. 309-317.

21 Shlimas D. I., Zdorovets M. V. and Kozlovskiy A. L. Synthesis and resistance to helium swelling of Li 2 TiO 3 ceramics. Journal of Materials Science: Materials in Electronics, 2020, Vol. 31(15), pp. 12903-12912. 
22 Tekin $\mathrm{H}$. O. et al. Characterization of $\mathrm{SiO}_{2}-\mathrm{PbO}-\mathrm{CdO}-\mathrm{Ga}_{2} \mathrm{O}_{3}$ glasses for comprehensive nuclear shielding performance: Alpha, proton, gamma, neutron radiation. Ceramics International, 2019, Vol. 45(15), pp. 19206 - 19222.

23 Gladkikh T. et al. Changes in optical and structural properties of AlN after irradiation with C2+ ions of 40 keV. Vacuum, 2019, Vol. 161, pp. 103 - 110.

24 Kumar Ashok. Gamma ray shielding properties of PbO-Li2O-B2O3 glasses. Radiation Physics and Chemistry, 2017, Vol. 136, pp. $50-53$.

25 Kozlovskiy A. et al. Influence of He-ion irradiation of ceramic AlN. Vacuum, 2019, Vol. 163, pp. 45 - 51.

26 Rammah Y. S. et al. Synthesis, physical, structural and shielding properties of newly developed B 2 O $3-$ $\mathrm{ZnO}-\mathrm{PbO}-\mathrm{Fe}_{2} \mathrm{O}_{3}$ glasses using Geant4 code and WinXCOM program. Applied Physics A, 2019, Vol. 125(8), p. 523.

27 Gaikwad D. K. et al. Gamma ray shielding properties of $\mathrm{TeO}_{2}-\mathrm{ZnF}_{2}-\mathrm{As} 2 \mathrm{O} 3-\mathrm{Sm}_{2} \mathrm{O}_{3}$ glasses. Journal of Alloys and Compound, 2018, Vol. 765, pp. $451-458$.

28 Kozlovskiy A. L., Zdorovets M. V. Synthesis, structural, strength and corrosion properties of thin films of the type $\mathrm{CuX}(\mathrm{X}=\mathrm{Bi}, \mathrm{Mg}, \mathrm{Ni})$. Journal of Materials Science: Materials in Electronics, 2019, Vol. 30(12), pp. 1181911832.

29 Kadyrzhanov K. K. et al. Research of the shielding effect and radiation resistance of composite $\mathrm{CuBi}_{2} \mathrm{O}_{4}$ films as well as their practical applications. Journal of Materials Science: Materials in Electronics, 2020, Vol. 31(14), pp. 11729-11740. 